\title{
MAPAS DE RISCO DE VIOLÊNCIA
}

\author{
Marco Akerman \\ Médico, Professor de Saúde Coletiva da Faculdade de Medicina do ABC, Pesquisador do Cedec, \\ Coordenador de Saúde da Cassi - SP \\ Aylene Bousquat \\ Médica, Professora de Saúde Coletiva da Faculdade de Medicina do ABC, Pesquisadora do Cedec
}

$\mathrm{O}$ Programa Nacional de Direitos Humanos (Ministério da Justiça, 1996), com o objetivo de formular políticas públicas de promoção e de proteção aos direitos humanos, deparou-se com a escassez de dados quantitativos relativos ao tema. Como parte do seu desenvolvimento, o Programa prevê a construção de registros que possam orientar o enfrentamento da violência e a alocação de recursos públicos (PNDH em Movimento, 1997). Neste sentido, três projetos se destacam: desenvolvimento de um banco de dados sobre graves violações dos direitos humanos no período de janeiro de 1996 até os dias atuais, englobando grupos de extermínio, violência policial e racismo; impacto da violência nas grandes cidades brasileiras sobre o padrão de resolução de conflitos da população; e construção de mapas de risco de violência em quatro cidades brasileiras: São Paulo, Rio de Janeiro, Salvador e Curitiba.

O terceiro projeto, já concluído, foi desenvolvido em parceria com o Centro de Estudos de Cultura Contemporânea - Cedec, entre fevereiro de 1997 e abril de 1999. O objetivo é identificar diferenciais intra-urbanos em relação à violência. Os resultados mostraram diferenças entre os bairros de cada cidade no que diz respeito à qualidade de vida, aos padrões de criminalidade, etc. Todos os quatro mapas revelaram a necessidade de que houvesse unidade entre áreas geográficas de intervenção e dos sistemas de informação e de dados estatísticos das polícias civil e militar para melhorar as ações de segurança pública (Cedec, 1996a, 1996b, 1997a e 1997b).

A partir da parceria entre o Ministério da Justiça/Secretaria Nacional de Direitos Humanos e o Cedec, que desenvolveu a metodologia de elaboração dos mapas e construiu o de São Paulo, foram identificados parceiros para a produção dos mapas de Curitiba, Salvador e Rio de Janeiro: respectivamente, o Instituto de Pesquisa e Planejamento Urbano - IPPUC da Prefeitura Municipal de Curitiba; o Instituto de Saúde Coletiva/Departamento de Sociologia da UFBA; e o Instituto de Estudos da Religião - Iser. O Núcleo de Estudos da Violência - NEV/ USP exerceu papel de consultoria na etapa São Paulo do projeto. Os perfis distintos das instituições envolvidas garantiu o necessário caráter interdisciplinar do projeto, requisito fundamental para a abordagem da temática dos direitos humanos.

Além de apresentarem imagens cartográficas dos diferenciais quantitativos de características selecionadas de violência - homicídios, furtos (tentativas), roubos (tentativas), lesões corporais, acidentes de trânsito - entre bairros distintos de uma mesma cidade, os mapas estabeleceram associações entre os perfis de violência destes bairros e suas respectivas "qualidades de vida", expressas por indicadores compostos, formados por variáveis censitárias. Mais ainda, partindo do pressuposto de que a formulação de políticas de enfrentamento da violência urbana deva contar tanto com dados relacionados com a rede de proteção social da cidade quanto com informações da rede de segurança pública, os quatro mapas, analisaram se há, ou não, compatibilização geográfica destes dados. Mostrou-se também como é que os recursos públicos de segurança, no caso dos mapas, os efetivos policiais e viaturas, são alocados dentro do espaço urbano.

$O$ presente artigo relata os aspectos mais relevantes que nortearam a construção destes quatro mapas, destacan- 
do-se o da cidade de São Paulo. No final do artigo, as principais observações derivadas de cada um dos mapas são apresentadas.

\section{POR QUE EXPLORAR DIFERENÇAS INTRA-URBANAS?}

Estudos comparando níveis de violência entre países ou entre cidades tornam-se cada vez mais presentes nas publicações especializadas ou na imprensa (Yunes e Rajs, 1994; Folha de S.Paulo, 18/03/96, O Estado de S. Paulo, 14/07/96). Se a comparação entre países interessaria mais às organizações internacionais, nos seus planos de alocação de recursos para os governos nacionais, as comparações entre cidades fazem com que os poderes Executivos fiquem mais ou menos preocupados, dependendo da colocação de suas cidades no ranking em questão. Por exemplo, as autoridades paulistas reconhecem que a questão da segurança é preocupante na cidade de São Paulo, mas têm apresentado dados comparativos sobre criminalidade em outras cidades, buscando relativizar o problema: em São Paulo, segundo o governo, são assassinadas 48,5 pessoas por grupo de 100 mil habitantes; no Rio são 63,5; em Cali são 130 (1995); ${ }^{1}$ e em Atlanta (EUA) são 80 casos por 100 mil habitantes ( $O$ Estado de $S$. Paulo, 14/07/96).

Por outro lado, estudos que examinam como taxas agregadas - por exemplo, a taxa de 48,5 pessoas assassinadas por 100 mil habitantes para a cidade de São Paulo - distribuem-se entre os diferentes espaços internos de uma cidade, em comparação com características sociodemográficas locais, são ainda pouco explorados. Em outras palavras, estuda-se mais a magnitude absoluta do problema da violência do que os impactos diferenciais dentro do espaço urbano provocados por diferentes condições de vida (Stephens et alii, 1994).

Nas cidades brasileiras, como se sabe, existem diferenças importantes nas condições de vida entre os vários bairros e, portanto, os riscos que correm as pessoas que vivem em regiões diferentes ou os danos sofridos por eles também serão diferentes. Isso cria espaços segregados nas cidades, que mudam, cotidianamente, a vida nesses locais e, por conseqüência, a vida de toda a cidade (Caldeira, 1992). Nesses espaços observa-se carência importante de serviços públicos - como já demonstrado pelo Mapa da Inclusão/Exclusão Social da Cidade de São Paulo (Sposati, 1996) -, fazendo com que a população local, "privada da ação do poder público, torne-se presa fácil de grupos criminosos, que passam, em substituição ao poder público, a oferecer benefícios na área social." (Folha de S.Paulo, 18/02/97). Esses grupos transformam-se em verdadeiros detentores do poder local e, muitas vezes, com apoio dos próprios moradores que ali vivem, criam "verdadeiros feudos medievais, onde o senhor é o traficante, controlando a vida da comunidade em plena era de globalização (Folha de S.Paulo, 18/02/97).

Qualquer ação pública no sentido de enfrentar os problemas de sua região de forma eficaz não pode desconhecer essas diferenças, pois as áreas com maior probabilidade de seus habitantes sofrerem maiores danos ou segregação devem ter por parte de sua administração um cuidado diferenciado.

A ação sobre o "pequeno" espaço não deve ficar restrita apenas ao campo da eficácia administrativa da gestão pública, mas também ser abordada dentro de uma estratégia de redefinição sociocultural do espaço urbano local. A valorização do espaço local pode "abrir uma grande oportunidade para a sociedade retomar as rédeas do seu próprio desenvolvimento" (Dowbor, 1995), pois se o que "é global separa; é o local que permite a união" (Santos, 1994). Tais interpretações sobre o espaço local encontram também fundamentação em trabalho de Friedmann (1992), em que declara que o empowerment, ou recuperação da cidadania, através do espaço local, do espaço do cidadão, é essencial.

Vale assinalar que não basta apenas indicar áreas onde o problema é mais grave; o que importa é a busca de uma nova articulação entre espaços distintos. Como aponta Milton Santos (apud Dowbor, 1995), "a base da ação reativa é o espaço compartilhado no cotidiano". Está tornando-se lugar-comum falar da globalização econômica através da interconexão das diversas economias do mundo e da ligação entre os países pelas redes de computadores. Deveríamos pensar nas nossas cidades da mesma forma. Se nossos destinos se encontram entrelaçados globalmente, certamente estão os nossos bairros dentro das nossas cidades (Cisneros, 1994).

Em vista de experiência já acumulada em análises que buscam aprofundar os diferenciais intra-urbanos na cidade de São Paulo, o Centro de Estudos de Cultura Contemporânea - Cedec foi convidado pelo Ministério da Justiça para elaborar "Mapas de Risco da Violência" nos municípios de São Paulo, Curitiba, Salvador e Rio de Janeiro. Esse convite veio no bojo da elaboração do Programa Nacional de Direitos Humanos, que tem como um dos seus objetivos "eleger prioridades e apresentar propostas concretas de caráter administrativo que busquem 
solucionar problemas relacionados à área dos direitos humanos no Brasil (Ministério da Justiça, 1996)". O Ministério da Justiça entendeu que determinar o risco territorial de violência consiste uma importante estratégia para a indicação de prioridades públicas e de desenvolvimento de projetos de ação local.

\section{IMPLICAÇÕES PRÁTICAS DE UM MAPA DE VIOLÊNCIA}

Um mapa é uma representação gráfica, em superfície plana, de uma paisagem geográfica. A escritora mineira Adélia Prado escreveu em Terra de Santa Cruz que "as legendas dos mapas são tão belas que dispensam as viagens" (apud Rónai, 1985). O mapa traz as imagens de uma dada realidade, desobrigando o leitor de estar presente no local representado.

No caso da violência, por mais que se cuide das legendas, estas não poderão mostrar um quadro belo da realidade. Os mapas estarão apenas dando visibilidade ao contraste entre os diversos territórios de uma cidade, seja em relação às condições socioeconômicas, aos recursos públicos disponíveis, ou aos danos sofridos pelas populações que aí vivem seu cotidiano.

O apelo visual dos mapas, no entanto, facilita sua difusão para um público mais amplo, uma vez que a linguagem cartográfica, numa sociedade tão desigual como a nossa, pode ser mais acessível que a linguagem escrita. Mais ainda, sua utilização pela mídia pode favorecer a sensibilização da sociedade em relação ao problema. Por outro lado, quando alguém reconhece no mapa o seu local de residência, provavelmente, terá um sentimento de maior identificação com o problema apontado.

Entretanto, se um mapa é um retrato estático da realidade, os riscos a que os indivíduos estão expostos não o são, pois estes mudam cotidianamente, o que permite a elaboração de mapas que retratem a realidade em distintos momentos, compondo um quadro que demonstra, como se fosse um filme, as diferentes situações de risco ao longo do tempo. Neste movimento, fica evidente que o tempo não é imune à ação do homem.

Essa historicidade do risco fica evidente quando se aborda a questão da violência no mundo e, em particular, no Brasil. Dados da Organização Pan-Americana de Saúde mostram que, entre 1979 e 1990, em nove países Argentina, Canadá, Costa Rica, Chile, Estados Unidos, México, Suriname, Trinidad Tobago e Venezuela -, a mortalidade por violência (causas externas) apresentou tendência declinante para todos os grupos de idade estudados. Em contraste, Brasil, Colômbia e Cuba mostram tendências francamente crescentes nas taxas de mortalidade por violência (Yunes e Rajs, 1994). Ressalte-se que se trata de taxas muito agregadas e que, conseqüentemente, não dão conta das diferenças entre classes socioeconômicas, grupos étnicos, gênero e regiões. Chama-se apenas atenção para o fato de que os danos sofridos ao longo do tempo pelas populações modificam-se, o que traz um alento, pois, se as ações ocorreram a curto prazo, o quadro atual da violência no Brasil é passível de ser modificado.

\section{ANÁLISE DE RISCO E ÊNFASE NA INTER-SETORIALIDADE}

Risco é um conceito de probabilidade e significa a chance que um indivíduo ou uma população tem de sofrer um dano futuro no seu equilíbrio vital, sendo que a eclosão desse dano está associada às condições de vida dos indivíduos e das populações. Para Locker (1992), medidas das características socioeconômicas por áreas geográficas podem ser melhores indicadores de condições de vida de subgrupos populacionais do que aquelas referentes a indivíduos ou famílias.

Trata-se aqui de introduzir a idéia de risco coletivo ao qual que está submetida uma determinada população que vive num dado território. Como esse risco coletivo não é um somatório dos riscos individuais das pessoas que ali vivem, importa então conhecer as condições dos espaços territoriais urbanos. A análise de risco, tradicionalmente, busca identificar, dentre todos os fatores que determinam um dano, aquele que mais contribuiria para sua ocorrência, indicando a ação prioritária sobre esse único fator. Entretanto, entende-se hoje que os fenômenos atuais não comportariam tal tipo de análise, devendo ser entendidos como fenômenos complexos, não em termos da dificuldade para sua compreensão, mas no sentido de que a sua determinação não se dá pela preponderância de um fator sobre outros, mas sim pela sinergia e inter-conexão de todos os fatores envolvidos (Schramm e Castiel, 1992).

Como essa idéia seria aplicada ao campo da violência? Para a ocorrência de um crime são necessários quatro fatores: motivos, meios, oportunidade e falta de controle. Deve haver uma pessoa motivada, com os meios para cometer o crime, oportunidades apresentadas por uma vítima vulnerável e falta de possibilidades para se evitar o crime pela ausência ou de controles externos - polícia, segurança, judiciário -, ou de controles internos, isto é, a 
consciência (Reiner, 1994). Dada a natureza destes fatores, a violência poderia ser entendida como um fenômeno complexo, em que a interação e a sinergia dos motivos, meios, oportunidades e controles estariam determinando o fenômeno, sem a preponderância de nenhum deles sobre os demais.

Como cada um desses fatores usualmente relaciona-se com áreas distintas das políticas públicas, um primeiro caminho a ser trilhado nessa análise de risco coletivo compreende a caracterização das condições de vida, de um dado espaço, por meio de um medida sintética - indicador composto -, que inclua diversas variáveis representando distintas áreas de ação pública. Nesse processo de medida, embutem-se a noção e a necessidade da abordagem inter-setorial que vem sendo propugnada por autores, profissionais, agências de fomento e organizações públicas que atuam na área de planejamento urbano, em geral, e na área da saúde, em particular, como um dos princípios fundamentais para o enfrentamento sustentável dos problemas que acometem as populações humanas (Werna, 1994). Recentemente, o projeto "Cidades Saudáveis", da OMS, resgatou mais uma vez a necessidade da inter-setorialidade e fez dessa condição fator relevante para o sucesso da proposta (Duhl, 1993, Werna, 1995).

Pareto (1992) ilustra o porquê da necessidade de se buscar formas de superação da ótica setorial: "Na prática, a maioria dos projetos e programas têm uma forte conotação setorial, refletindo a estrutura da administração urbana. Se não existir um planejamento que coordene os setores, cada um irá propor seu próprio projeto, baseado em sua visão da realidade urbana, e estabelecerá seus próprios objetivos e métodos. Assim sendo, os setores com maior poder político irão provavelmente receber maior fatia dos recursos disponíveis, enquanto os mais fracos terão que competir pelas sobras. Este processo tende a agravar as distorções e as desigualdades já existentes no espaço urbano". Tal citação reforça a necessidade da busca de forma ativa e obstinada da abordagem inter-setorial como um caminho adequado para a superação dos problemas que levam à violência urbana.

Dentro dessa perspectiva, todos os quatro mapas utilizaram algum tipo de indicador composto que incluiu diversas variáveis representando distintas áreas de ação pública, com o intuito claro de enviar a mensagem de que o fenômeno da violência é multicausal e pressupõe abordagem inter-setorial. O Mapa de Risco da Violência da Cidade de São Paulo utilizou um indicador composto - chamado "nota socioeconômica" - que será detalhado no tópico a seguir.

A elaboração dos quatro mapas mostrou a limitação dos dados existentes nos bancos de dados oficiais para caracterizar, de forma abrangente, a complexidade do fenômeno da violência urbana. A limitação e a escassez ganharam dimensão ainda maior quando considerou-se a desagregação deste tipo de dado para espaços menores. As informações sobre homicídios, entretanto, nas quatro cidades, foram as únicas que se mostraram disponíveis para análise desagregada por espaços menores. Apesar de os dados relacionados ao homicídio conterem apenas parte da dimensão da violência urbana e do desrespeito aos direitos humanos, seu caráter trágico e epidêmico permite que a representação da sua distribuição desigual no espaço urbano ofereça pistas para, talvez, a distribuição desigual de todas as outras dimensões da violência urbana e do desrespeito aos direitos humanos.

\section{A CIDADE DE SÃO PAULO: A CONSTRUÇÃO DO "MAPA DE RISCO DISTRITAL"}

A Tabela 1 traz o retrato do chamado "risco distrital". Foram considerados os 96 distritos do Município de São Paulo, divisão fixada na Lei no 11.220 , de 20 de maio de 1992. A população dos distritos e da cidade foi estimada, para 1995, aplicando-se o percentual de $1 \%$ ao ano, a partir da população apurada pelo Censo de 1991 para o Município de São Paulo. ${ }^{2}$

Para compor as notas socioeconômicas dos distritos o indicador composto -, foram utilizadas duas fontes e os respectivos indicadores: Censo IBGE 1991 - "porcentagem de chefes de família sem rendimento"; "porcentagem de chefes de família com renda acima de 20 salários mínimos; "porcentagem de chefes de família com 1 a 3 anos de estudo"; "porcentagem de chefes de família com mais de 15 anos de estudo; "número de pessoas por domicílio"; "número de pessoas por banheiros"; "acesso precário à rede de água"; "acesso precário à rede de esgoto"; "acesso precário à coleta de lixo" - e Banco de dados do Mapa da Exclusão Social da Cidade de São Paulo - "taxa de emprego". Foram criados ainda dois outros indicadores: "potencial de renda" e "potencial educacional", que mediram a discrepância intradistrital entre os dois extremos de renda e educação. ${ }^{3}$ Apenas para citar alguns exemplos, o Jardim Paulista, Moema, Alto de Pinheiros, Pinheiros e Perdizes foram caracterizados como distritos com as melhores condições socioeconômicas, 
TABELA 1

Risco Distrital por Homicídio Relacionado às Notas Socioeconômicas Município de São Paulo - 1995

\begin{tabular}{|c|c|c|c|c|c|c|c|c|c|}
\hline Distritos & $\begin{array}{l}\text { População } \\
\text { Estimada }\end{array}$ & $\begin{array}{c}\text { Nota Socio- } \\
\text { econômica }\end{array}$ & $\begin{array}{l}\text { Óbitos por } \\
\text { Homicídio }\end{array}$ & $\begin{array}{c}\text { Taxas por } \\
\text { Homicídio/ } \\
100.000 \text { hab. }\end{array}$ & Distritos & $\begin{array}{c}\text { População } \\
\text { Estimada }\end{array}$ & $\begin{array}{l}\text { Nota Socio- } \\
\text { econômica }\end{array}$ & $\begin{array}{l}\text { Obitos por } \\
\text { Homicídio }\end{array}$ & $\begin{array}{c}\text { Taxas por } \\
\text { Homicídio/ } \\
100.000 \text { hab. }\end{array}$ \\
\hline \multirow{3}{*}{$\begin{array}{l}\text { Município de } \\
\text { São Paulo }\end{array}$} & & & & & Campo Grande & 85.383 & 4,79 & 28 & 32,79 \\
\hline & 10.037 .820 & & 4.275 & 42,59 & Cangaíba & 119.742 & 3,74 & 39 & 32,57 \\
\hline & & & & & Cursino & 114.919 & 4,90 & 39 & 31,33 \\
\hline Jardim Ângela & 186.616 & 2,02 & 207 & 111,52 & Freguesia do Ó & 158.870 & 3,78 & 49 & 30,84 \\
\hline Grajaú & 201.620 & 2,35 & 205 & 101,06 & Campo Belo & 81.117 & 6,29 & 25 & 30,82 \\
\hline Parelheiros & 57.851 & 1,97 & 50 & 96,80 & Vila Medeiros & 162.479 & 3,54 & 50 & 30,77 \\
\hline Cidade Tiradentes & 100.190 & 2,85 & 89 & 88,83 & Jaraguá & 96.960 & 3,09 & 29 & 29,91 \\
\hline Capão Redondo & 201.353 & 2,24 & 168 & 83,44 & Perus & 48.181 & 2,52 & 14 & 29,06 \\
\hline Lajeado & 117.387 & 2,72 & 95 & 80,93 & Casa Verde & 100.310 & 4,53 & 29 & 28,91 \\
\hline Jardim São Luiz & 212.578 & 2,85 & 168 & 79,03 & Tremembé & 130.153 & 3,45 & 37 & 28,43 \\
\hline Sé & 28.290 & 4,60 & 22 & 77,77 & Artur Alvim & 123.343 & 3,90 & 35 & 28,36 \\
\hline Guaianases & 84.677 & 3,26 & 62 & 73,22 & São Domingos & 73.244 & 4,11 & 20 & 27,31 \\
\hline Brás & 34.898 & 4,51 & 25 & 71,64 & Água Rasa & 98.960 & 4,35 & 27 & 27,29 \\
\hline Vila Curuçá & 129.347 & 3,30 & 90 & 69,58 & Vila Matilde & 113.449 & 4,31 & 30 & 26,44 \\
\hline Cachoeirinha & 130.962 & 3,30 & 88 & 67,20 & Pirituba & 158.489 & 3,61 & 41 & 25,87 \\
\hline Itaim Paulista & 169.898 & 2,57 & 112 & 65,92 & Raposo Tavares & 96.256 & 3,30 & 22 & 25,51 \\
\hline Iguatemi & 62.249 & 1,57 & 41 & 65,80 & Itaim Bibi & 111.861 & 6,05 & 28 & 25,03 \\
\hline Jd. Helena & 123.187 & 2,04 & 81 & 65,75 & Ipiranga & 105.655 & 4,97 & 25 & 24,61 \\
\hline Cidade Dutra & 175.675 & 3,05 & 113 & 64,32 & Vila Prudente & 118.937 & 4,06 & 28 & 23,51 \\
\hline Campo Limpo & 165.9946 & 3,02 & 105 & 63,27 & Anhangüera & 12.912 & 1,61 & 3 & 23,23 \\
\hline Brasilândia & 209.776 & 2,49 & 131 & 62,45 & Belém & 51.715 & 4,93 & 12 & 29,29 \\
\hline Cidade Ademar & 240.164 & 3,18 & 143 & 59,54 & Vila Sônia & 86.376 & 4,63 & 20 & 23,15 \\
\hline Vila Jacuí & 105.346 & 3,04 & 61 & 57,90 & Jaguara & 31.008 & 4,27 & 7 & 28,07 \\
\hline São Mateus & 156.885 & 2,86 & 88 & 58,09 & Consolação & 69.294 & 6,63 & 15 & 21,65 \\
\hline Sapopemba & 268.076 & 2,44 & 146 & 54,46 & Saúde & 131.736 & 5,73 & 27 & 20,59 \\
\hline Ermelino Matarazzo & 99.491 & 3,05 & 54 & 54,28 & Santa Cecilia & 89.314 & 5,60 & 18 & 20,15 \\
\hline Pedreira & 89.493 & 2,48 & 48 & 53,64 & Butanta & 60.375 & 5,37 & 12 & 19,96 \\
\hline São Miguel & 107.144 & 3,27 & 55 & 51,33 & Tucuruvi & 116.426 & 4,61 & 23 & 19,75 \\
\hline Vila Leopoldina & 27.916 & 5,03 & 14 & 50,15 & São Lucas & 156.209 & 3,76 & 30 & 18,96 \\
\hline Aricanduva & 100.430 & 3,37 & 48 & 47,79 & Ponte Rasa & 106.872 & 3,72 & 20 & 18,71 \\
\hline Vila Andrade & 44.305 & 3,93 & 21 & 47,40 & Vila Gullherme & 64.127 & 4,49 & 12 & 18,71 \\
\hline Socorro & 44.948 & 4,78 & 21 & 46,72 & $\begin{array}{l}\text { Carrao } \\
\text { Bom Retiro }\end{array}$ & 90.882 & 4,27 & 17 & 18,71 \\
\hline Sacomã & 219.775 & 4,19 & 102 & 48,41 & Bom Retlio & 37.603 & 4,62 & 7 & 18,62 \\
\hline Morumbi & 41.656 & 5,22 & 19 & 45,61 & $\begin{array}{l}\text { IVIandaqul } \\
\text { Lapa }\end{array}$ & $\begin{array}{r}108.245 \\
73174\end{array}$ & $\begin{array}{l}4,56 \\
590\end{array}$ & 20 & $\begin{array}{l}18,45 \\
17,77\end{array}$ \\
\hline Cidade Líder & 101.323 & 3,51 & 46 & 45,40 & $\begin{array}{l}\text { Liperdade } \\
\text { Liber }\end{array}$ & $\begin{array}{l}13.1 / 4 \\
79.341\end{array}$ & $\begin{array}{l}5,90 \\
5,42\end{array}$ & $\begin{array}{l}13 \\
14\end{array}$ & $\begin{array}{l}17,17 \\
1785\end{array}$ \\
\hline São Rafael & 93.510 & 2,30 & 42 & 44,91 & Penha & 138.406 & $\begin{array}{l}5,42 \\
4,22\end{array}$ & $\begin{array}{l}14 \\
24\end{array}$ & $\begin{array}{l}17,85 \\
17,34\end{array}$ \\
\hline Jabaquara & 223.053 & 4,14 & 99 & 44,38 & Alto de Pinheiros & 52.395 & 7,20 & 9 & 17,18 \\
\hline Parque do Carmo & 56.966 & 2,86 & 25 & 43,89 & Marsilac & 6.235 & 0,87 & 1 & 16,04 \\
\hline José Bonifácio & 107.923 & 3,84 & 47 & 43,55 & Mooca & 74.922 & 5,51 & 12 & 16,02 \\
\hline Jaguaré & 46.162 & 4,13 & 19 & 41,16 & Pari & 22.164 & 4,85 & 3 & 13,54 \\
\hline Vila Maria & 127.642 & 3,60 & 51 & 39,96 & Santana & 143.269 & 5,96 & 19 & 13,26 \\
\hline Santo Amaro & 78.624 & 6,66 & 29 & 36,88 & Jardim Paulista & 107.325 & 8,44 & 14 & 13,04 \\
\hline Jaçanã & 90.355 & 3,63 & 33 & 38,52 & Cambuci & 58.574 & 5,04 & 5 & 12,96 \\
\hline Limão & 94.093 & 4,33 & 34 & 36,13 & Tatuapé & 65.163 & 5,33 & 11 & 12,92 \\
\hline Barra Funda & 16.626 & 5,76 & 6 & 36,09 & Moema & 80.480 & 7,92 & 10 & 12,43 \\
\hline Rio Pequeno & 106.904 & 3,87 & 38 & 35,53 & Pinheiros & 81.837 & 7,10 & 10 & 12,22 \\
\hline Vila Formosa & 101.916 & 3,91 & 36 & 35,32 & Bela Vista & 74.741 & 6,19 & 9 & 12,04 \\
\hline Itaquera & 182.486 & 3,53 & 63 & 34,52 & Vila Mariana & 138.215 & 6,26 & 18 & 11,58 \\
\hline República & 60.144 & 6,99 & 20 & 33,25 & Perdizes & 119.290 & 7,0 & 3 & 2,65 \\
\hline
\end{tabular}

Fonte: Fundação IBGE, 1991; PRO-AIM, 1995. 
respectivamente com as notas 8,44, 7,92, 7,20, 7,10 e 7,00, enquanto Marsilac, Iguatemi, Anhangüera, Parelheiros e Jardim Ângela obtiveram as notas mais baixas, respectivamente, $0,87,1,57,1,61,1,97$ e 2,02.

As taxas de homicídio (por 100 mil habitantes) foram produzidas com dados de mortalidade (1995) fornecidos pelo Programa de Acompanhamento de Indicadores de Mortalidade do Município de São Paulo (PRO-AIM). Estas taxas, classificadas em ordem decrescente, permitem observar, grosso modo, uma associação entre menores notas socioeconômicas/maiores taxas de homicídios e maiores notas/menores taxas. A Tabela 1, portanto, sugere que haveria uma associação importante entre condições socioeconômicas e risco de violência, aqui representada pela taxa de homicídios.

Para fins de políticas de direitos humanos, em última instância a razão maior da construção desse mapa de risco, cabe uma estratificação dos distritos em função de seus riscos. Dada a conformação administrativa do Município de São Paulo e sua disponibilidade de recursos, seria inviável, do ponto de vista macro, estabelecer 96 tipos de ações de acordo com as especificidades de cada distrito. Assim, toma-se como referência a taxa do Município de São Paulo (42,59 homicídios por 100 mil habitantes), partindo-se do pressuposto que, no mínimo, deva-se estabelecer a meta de alcançar riscos distritais que, pelo menos, não ultrapassem a taxa da cidade. ${ }^{4}$

A aplicação de um procedimento estatístico ${ }^{5}$ permitiu a produção de três estratos de risco diferenciados, em que 22 distritos (taxas entre 2,65 e 18,96) foram classificados como de baixo risco, 59 (taxas entre 19,75 e 64, 32) como de médio risco e 15 (taxas entre 65,75 e 111,52) de alto risco.

Cabe reafirmar que mesmo a taxa do Município de São Paulo é ainda muito alta em relação aos padrões internacionais, mas, para efeito da definição de parâmetros a serem alcançados para os distritos de alto risco, a taxa da cidade pode ser um bom começo.

\section{DISTRIBUIÇÃO DESIGUAL DAS POLÍTICAS PÚBLICAS}

Apesar da complexidade do fenômeno da violência por homicídio, devido aos fatores múltiplos que interagem na determinação dos assassinatos, e da sua visibilidade pública, entende-se que o homicídio não pode ser considerado o único evento violento passível de análise. A compatibilização entre os dados disponíveis dos distritos (96) da cidade de São Paulo e das
Delegacias Seccionais de Polícia (8), efetuada na elaboração do Mapa de Risco da Violência de São Paulo (para maiores detalhes ver Cedec, 1996a), permitiu incluir na análise outros eventos violentos - furtos (e tentativas) e roubos (e tentativas).

Diferentemente do que ocorre com as taxas de homicídio, existe uma relação inversa entre os furtos e os roubos e as condiçõos socioeconômicas das áreas abrangidas pelas seccionais de polícia. Isto é, as seccionais com as melhores notas socioeconômicas apresentam maiores proporções de furtos e roubos e maiores riscos para lesões corporais e acidentes de trânsito, ganhando destaque, neste último caso, a região central da cidade, devido, provavelmente, à sua população flutuante, muito maior que a residente.

Quando comparados os riscos por homicídios e furtos, observa-se um padrão que chama a atenção. As três seccionais com as menores notas socioeconômicas apresentam os três maiores riscos para o homicídio e os três menores para os furtos.

Uma forma possível de aproximar a análise de como o poder público enfrenta esses riscos de violência consiste num balanço dos efetivos policiais existentes (militares e civis) ${ }^{6}$ e viaturas efetivamente funcionando (militares e civis) no Município de São Paulo, a partir de dados fornecidos, exclusivamente para o presente projeto, pelo Deplan da Polícia Civil e pelo Comando de Policiamento Metropolitano da Polícia Militar. Aqui, procedeu-se a um outro exercício de compatibilização, agora entre Companhias Militares e Delegacias Seccionais, uma vez que muitas Companhias Militares se dividem entre mais de uma seccional.

A análise geral desses dados mostrou que aqueles recursos de segurança pública concentram-se mais nas seccionais onde os furtos apresentam maior proporção e se distribuem de uma forma mais esparsa naqueles onde os maiores riscos de violência são atribuídos ao homicídio. ${ }^{7}$

Os resultados obtidos a partir dessa análise evidenciam as prioridades que vêm sendo implementadas pelos órgãos de segurança pública no município, que contemplam prioritariamente os crimes contra o patrimônio, que ocorrem nas áreas com as melhores condições socioeconômicas.

\section{UMA SÍNTESE DOS QUATRO MAPAS}

A seguir, apresentam-se as principais observações derivadas dos quatro mapas, não à guisa de conclusão, mas como uma contribuição para a continuidade do debate 
sobre aprimoramento do sistema de informação de segurança pública e direitos humanos e sobre a busca de caminhos para o enfrentamento da violência urbana e do desrespeito aos direitos humanos.

\section{São Paulo}

A eficácia do enfrentamento do fenômeno da violência estaria associada ao modo de compreendê-lo. Devido à natureza dos seus determinantes, a violência poderia ser entendida como um fenômeno complexo produzido pela sinergia e interação dos seus vários determinantes, sem a preponderância de nenhum deles sobre os demais. A aceitação dessa premissa sugeriria que toda e qualquer intervenção sobre essa problemática tem que vir acompanhada de uma estratégia intersetorial. A "nota socioeconômica", enquanto medida sintética das condições de vida, cumpre o papel de chamar atenção para a necessidade de analisar o problema sob uma ótica inter-setorial.

A análise do "risco distrital", que sugere um padrão de redução para as taxas de homicídio na cidade de São Paulo, indica que o engajamento em ações nesse campo deve ser antecedido pela fixação de parâmetros objetivos que possam balizar o sucesso ou insucesso das ações empreendidas. O mapa é apenas um retrato espacial do problema analisado dentro do contexto de uma temporalidade única. Importa, antes de tudo, o acompanhamento do problema ao longo do tempo, uma vez que o presente projeto - Mapa de Risco da Violência - não objetiva apenas descrever a situação, mas, fundamentalmente, criar bases para monitoramento e intervenção. A fixação de parâmetros objetivos explicita o "tamanho" do problema e estimula os atores sociais envolvidos a redefinirem, ao longo do tempo, seus padrões de sucesso e avaliarem eventuais fracassos.

A compatibilização dos dados disponíveis dos distritos censitários com os dados das Delegacias Seccionais indica que deve haver um esforço das instâncias governamentais no sentido de construírem áreas geográficas de abrangência que sejam compatíveis entre si para que o "olhar" sobre o território urbano não seja descoordenado. Como ressalta Dowbor (1995), "essa rearticulação passa por uma redefinição da cidade e, em particular, por uma redefinição das instituições para que os espaços participativos coincidam com as instâncias de decisões significativas. As hierarquizações tradicionais dos espaços tornaram-se insuficien- tes ou inadequadas". Citando Ianni, Dowbor (1995) reitera que "o todo parece uma expressão diversa, estranha, alheia às partes, e estas permanecem fragmentadas, dissociadas, reiterando-se aqui ou lá, ontem ou hoje, como que extraviadas, em busca de seu lugar".

As ações de segurança pública poderiam ser mais eficazes se houvesse a unidade entre os sistemas de informação de dados estatísticos das Polícias Civil e Militar.

A alocação prioritária de recursos de segurança pública vem se dando em áreas geográficas onde predomina o crime contra o patrimônio - no caso analisado, os furtos de veículos -, ao passo que as áreas onde predominam os homicídios recebem menores contingentes policiais e menores números de viaturas por habitante. Como já mencionado, ao contrário dos homicídios, os furtos e roubos predominam em áreas centrais habitadas por populações com melhores condições de vida. Tal padrão de alocação de recursos públicos, priorizando áreas mais centrais e com melhores condições socioeconômicas em detrimento de áreas periféricas, parece repetir-se, também, em relação às outras políticas sociais (Sposati, 1996), não se configurando, portanto, como aspecto específico da área de segurança pública. Mais uma vez, demonstra-se a necessidade da abordagem inter-setorial no enfrentamento da violência urbana.

\section{Curitiba}

Apesar da maior participação dos acidentes de trânsito como causa de mortes violentas, os mesmos vêm apresentando tendência de estabilização, ou até decréscimo. Em contraposição, os homicídios, que registram taxas mais baixas em comparação com outras cidades, vêm mostrando tendência de crescimento.

Não existe um sistema de informação de segurança pública estruturado. Dessa forma, registrar ou não os dados, quais dados registrar, com que critério e com que nível de detalhamento dependem, em grande parte, do interesse do delegado ou da autoridade de segurança pública que exerce o cargo no momento.

Não há unidade entre as áreas geográficas da rede de proteção social e os sistemas de informação e estatística das Polícias Civil e Militar.

A comparação da distribuição, em números absolutos, dos homicídios conforme o local de residência e de ocorrência mostra uma correlação significativa, indicando que, com exceção do centro, as pessoas estão sendo vitimadas no próprio bairro de moradia. 
O Mapa de Risco da Violência da Cidade de Curitiba desencadeou um conjunto de ações que visam enfrentar a violência de maneira mais efetiva. O município assumiu esta questão como prioridade e instituiu uma coordenação para planejar e implantar ações em conjunto com outras instituições. A proposta recebeu o nome de "Rede Integrada de Segurança" para atuar tanto nos aspectos de repressão à violência quanto nos de prevenção.

\section{Salvador}

Existe um predomínio de elevados coeficientes de mortalidade por homicídio nos bairros com piores condições de vida.

Não há um estudo sistemático das declarações de óbito, o que dificulta o monitoramento das mortes por causas externas a longo prazo.

Quatro aspectos destacam-se na avaliação geral das informações sobre o diagnóstico da criminalidade e a atuação das Polícias, bem como suas implicações sobre violências e mortes:

- falta de integração operacional entre as duas Polícias;

- poucos recursos humanos, em especial aqueles que atuam diretamente com a criminalidade, pois existe grande deslocamento de efetivos para atividades administrativas de apoio;

- significativa carência de equipamentos, em quantidade e grau de atualização tecnológica;

- baixo padrão de estrutura organizacional dos órgãos de segurança pública.

\section{Rio de Janeiro}

O Mapa de Risco da Violência do Rio de Janeiro encontrou uma cidade institucionalmente descoordenada, em que cada órgão subdivide a cidade de acordo com sua lógica; resultado: o cidadão perde sua identidade espacial, perde o acesso a informações públicas, burocraticamente privatizadas.

$\mathrm{O}$ risco de morrer assassinado distribui-se desigualmente pelo espaço urbano, entre bairros e/ou regiões administrativas. Seria importante a construção de um sistema de informações que permitisse a compatibilização dos dados das delegacias com os dos órgãos administrativos da prefeitura, o que facilitaria o planejamento de ações de enfrentamento da violência.

\section{CONSIDERAÇÕES FINAIS}

Para finalizar, vale a pena mencionar que o Mapa de Risco da Violência da Cidade de São Paulo teve seus resultados divulgados na imprensa local e nacional, o que favoreceu uma ampliação do diálogo com a sociedade civil, caracterizando o projeto não como uma iniciativa acadêmica, mas sim enquanto um instrumento que possa influenciar políticas.

A título de exemplo, um artigo publicado em um grande jornal de circulação nacional comentou um crime violento ocorrido numa área nobre da cidade. Citando dados do mapa para caracterizar a magnitude da violência e seus determinantes entre o centro e a periferia da cidade, esse artigo utilizou como manchete a frase "os lugares do crime", em última estância uma abordagem dos diferenciais intra-urbanos (Gonçalves, 1996).

Ao se retratar nesse artigo a questão das diferenças entre espaços urbanos e seu impacto sobre a violência na cidade, avaliou-se que o Mapa de Risco da Violência da Cidade de São Paulo demonstrou a sua capacidade de transmitir a mensagem da importância das diferenças intraurbanas na compreensão e na intervenção sobre o problema da violência.

\section{NOTAS}

E-mail dos autores: akerman.ops@terra.com.br / aylenebousquat@uol.com.br

1. A taxa de Cali apresentada pelo artigo do jornal foi de 300/100.000. A taxa de 130/100.000 teve como fonte trabalho produzido pelo Ministério da Saúde da Colômbia (1996).

2. Esta foi a taxa de crescimento anual medida pelo IBGE entre 1980-1991 para o Município de São Paulo.

3. Maiores detalhes sobre os critérios de escolha das variáveis e métodos utilizados para a criação do indicador composto - "notas socioeconômicas" - podem ser obtidos com o Cedec

4. O mapa representando esses estratos está publicado em Cedec (1996a) e pode ser obtido com os autores do presente artigo.

5. Taxa de homicídio de São Paulo em $1995=42,59 / 100.000$ hab.

Desvio-Padrão das taxas distritais $=23$.

Cálculo dos estratos de risco:

$-42,59+23=65,59-$ Todos os distritos com taxas acima desse valor foram classificados no estrato de alto risco;

- 42,59 - $23=19,59$ - Todos os distritos com taxas abaixo desse valor foram classificados no estrato de baixo risco;

- todos os distritos com taxas entre 19,59 e 65,59 foram classificados como distritos de risco intermediário.

6. Para o cálculo dos efetivos militares não foram considerados os batalhões de polícia feminina e batalhões de trânsito, nem pessoal lotado na sede do Comando de Policiamento de Área da Polícia Militar CPA. Quanto aos efetivos civis foram considerados os investigadores e agentes. Estes dados são relativos ao ano de 1995.

7. Há que se ressaltar, entretanto, que os dados calculados para a $1^{\text {a }}$ Seccional (Centro) devem ser relativizados em função do alto fluxo de pessoas na região durante o dia. 


\section{REFERÊNCIAS BIBLIOGRÁFICAS}

CALDEIRA, T.P.R. City of walls: crime, segregation and citizenship in São Paulo. Dissertação submetida à Antropology Graduate Division of University of California at Berkeley, 1992.

CEDEC. Mapa de Risco da Violência da Cidade de São Paulo. São Paulo, 1996a. . Mapa de Risco da Violência da Cidade de Curitiba. São Paulo, $1996 \mathrm{~b}$. $1997 \mathrm{a}$. Paulo, 1997b.

CISNEROS, H. Urban poverty and urban environment in the north. Paper present at the Second Annual World Bank Conference on Environmentally Sustainable Development, The Human Face of The Urban Environment. September, 19-21, 1994

DOWBOR, L. "Da globalização ao poder local: a nova hierarquia dos espaços". São Paulo em Perspectiva. São Paulo, Fundação Seade, v.9, n.3, 1995, p.3-10.

DUHL, L. "Conditions for healthy cities, diversity, game boards and social entrepreneurs". Environment and Urbanization. Londres, IIED, v.5, n.2, 1993, p.112-124.

FOLHA DE S.PAULO. "Estudo mostra que Colômbia é mais violenta do que o Brasil". São Paulo, primeiro caderno, 18/03/96, p.9.

. "Editorial: refém da violência". São Paulo, primeiro caderno, 18/02/97, p.2.

FRIEDMANN, J. Empowerment: the politics of alternative development. Cambridge, Blackwell, 1992.

GONÇALVES, M.A. "Os lugares do crime”. Folha de S.Paulo. São Paulo, primeiro caderno, coluna "Domingueira", 18/08/96.

IANNI, O. A idéia do Brasil moderno. São Paulo, Brasiliense, 1992.

LOCKER, D. Measuring social inequality in dental health services research: individual, household and area-based measures. Toronto, Department of Community Dentistry and Community Dental Health Services Research Unit, Faculty of Dentistry, University of Toronto, 1992.
MINISTÉRIO DA JUSTIÇA. Programa Nacional de Direitos Humanos. Brasília, Ministério da Justiça, 1996.

MINISTÉRIO DA SAÚDE DA COLÔMBIA. Actos violentos en Colombia. Santa Fé de Bogotá, Ministério de Salud, 1996.

O ESTADO DE S. PAULO. "Covas libera verbas e aponta estatísticas". São Paulo, caderno A, 14/07/96, p.11.

PARETO, V.E. "A model to access urban conditions and dimension development project." Habitat International, n.16, v.14, 1992, p.99-117.

PNDH EM MOVIMENTO. "Construindo bases de dados". Brasília, Ministério da Justiça, ano I, n.1, set./out. 1997.

REINER, R. "Crime and control: an honest citizen guide". London School of Economicas Magazine Spring. Londres, LSE, 1994, p.10-13.

RÓNAI, P. Dicionário Universal Nova Fronteira de Citações. Rio de Janeiro, Nova Fronteira, 1985

SANTOS, M. Técnica, espaço, tempo globalização e meio técnico científico informacional. São Paulo, Hucitec, 1994.

SCHRAMM, F.R. e CASTIEL, L.D. "Processo saúde/doença e complexidade em epidemiologia". Cadernos de Saúde Pública. Rio de Janeiro, Fiocruz, v.8, n.4, 1992, p.379-390.

SPOSATI, A. (coord.). Mapa da inclusãolexclusão social da cidade de São Paulo. São Paulo, Educ, 1996.

STEPHENS, C. et alii. Environment and health in developing countries: an analysis of intra-urban mortality differentials using existing data in Accra (Ghana) e São Paulo (Brazil) and analysis of urban data of four Demographic and Health Surveys. Londres, London School of Hygiene and Tropical Medicine, 1994.

YUNES, J. e RAJS, D. "Tendência de la mortalidade por causas violentas en la población general e entre los adolescentes y jóvenes de la región de las Américas". Cadernos de Saúde Pública. Rio de Janeiro, Fiocruz, v.10, Suplemento 1, 1994, p.88-125.

WERNA, E. United Nations Agencies Urban Policies and Health. Paper presented to the Conference Urban Health Research: implications for policy. London, London School of Hygiene and Tropical Medicine, 1994.

"The evaluation of healthy city projects in developing countries". Habitat International, v.19, n.3, 1995, p.1-13. 